\title{
The Estimation of Renewal Functions Using the Mean Value Theorem for Integrals (MeVTI) Method
}

\author{
Leopoldus Ricky Sasongko ${ }^{1 *}$, Tundjung Mahatma ${ }^{2}$ \\ ${ }^{1,2}$ Department of Mathematics, Faculty of Science and Mathematics, \\ Satya Wacana Christian University, Salatiga \\ *corresponding author email: leopoldus.sasongko@staff.uksw.edu
}

\begin{abstract}
In the analysis of warranty, renewal functions are important in acquiring the expected number of failures of a nonrepairable component in a time interval. It is very difficult and complicated -if at all possible- to obtain a renewal function analytically. This paper proposes a numerical integration method for estimating renewal functions in the terms of renewal integral equations. The estimation is done through the Mean Value Theorem for Integrals (MeVTI) method after modifying the variable of the renewal integral equations. The accuracy of the estimation is measured by its comparison against the existing analytical approach of renewal functions, those are for Exponential, Erlang, Gamma, and Normal baseline failure distributions. The estimation of the renewal function for a Weibull baseline failure distribution as the results of the method is compared to that of the well-known numerical integration approaches, the Riemann-Stieljies and cubic spline methods.
\end{abstract}

Keywords : Mean Value Theorem for Integrals, Renewal Functions, Renewal Integral Equations.

\section{Estimasi Fungsi Pembaruan Menggunakan Metode Mean Value Theorem for Integrals (MeVTI)}

\begin{abstract}
Abstrak
Dalam bidang analisis garansi, fungsi pembaruan berperan penting dalam perolehan ekspektasi banyak kegagalan suatu 'komponen yang tak dapat diperbaiki' di suatu selang waktu. Jika dimungkinkan, sangatlah sulit dan rumit memperoleh suatu fungsi pembaruan secara analitik. Makalah ini mengusulkan suatu metode integrasi numerik untuk mengestimasi fungsi pembaruan dalam bentuk persamaan integral pembaruan. Estimasi fungsi pembaruan dilakukan melalui metode Mean Value Theorem for Integrals (MeVTI) setelah memodifikasi peubah dalam persamaan integral pembaruan. Keakuratan estimasi tersebut diukur berdasarkan perbandingannya terhadap pendekatan analitik fungsi pembaruan untuk distribusi kegagalan dasar Eksponensial, Erlang, Gamma, dan Normal. Estimasi fungsi pembaruan untuk distribusi kegagalan dasar Weibull melalui metode MeVTI juga dilakukan dan hasilnya dibandingkan dengan hasil estimasi melalui metode Riemann-Stieljies dan spline kubik.
\end{abstract}

Kata kunci : Fungsi Pembaruan, Mean Value Theorem for Integrals, Persamaan Integral Pembaruan.

\section{Introduction}

In providing a warranty, one important thing that affects warranty cost of a component is the expected number of failures of the component in a time interval. For a special case, number of failures of a nonrepairable component (by assuming the replacement of the failed component with brand new one in negligibly short time) in a time interval follows renewal process, so the expected is obtained by renewal functions (RNFs). RNFs have an important role in analysis of warranty [1, 2]. Maghsoodlo and Helvaci [2] state that "renewal functions have wide variety of applications in decision making such as inventory theory, supply chain planning, continuous sampling plans, insurance application, and sequential analysis".

Obtaining a RNF analytically is very difficult and complicated for most baseline failure distributions (BFDs) such as Weibull BFD, the BFD that is often used in analysis of warranty [2,3]. Thus, obtaining the expected number of failures of a nonrepairable component in a time interval needs a long way and time, or maybe there is no solution to obtain it analytically. Therefore, development of computational techniques and approximations for RNFs has attracted many researchers [4].

Beside the analytical approach of RNFs, there are still four alternate approaches. The first approach is approximations those have three kind of approximations. The first approximation is asymptotic approximations. One of the asymptotic approximations is given by Täcklind [5] which a RNF involves the 
first and second raw moments $\left(\mu_{1}{ }^{\prime}\right.$ and $\left.\mu_{2}{ }^{\prime}\right)$ of a BFD. Moreover, Ross [6] and Cinlar [7] give an asymptotic approximation of a RNF which involves mean and variance $\left(\mu\right.$ and $\left.\sigma^{2}\right)$ of a BFD. However, the asymptotic approximations are not accurate or useful for small values of $t$ [8]. The second approximation is developed by using power series expansion. The approximation is often applied to obtain a RNF for a Weibull BFD. Smith and Leadbetter [9] develope a method to compute the RNF by using power series expansion of $t^{\beta}$ where $\beta$ is the shape parameter of the Weibull. Moreover, a method using the infinite series of appropriate Poisonian functions of $t^{\beta}$ is proposed by Lomnicki [10]. The third approximation is proposed by many researchers such as Bartholomew [11], Ozbaykal [12], and Deligönül [13] in which the RNFs (in the terms of renewal integral equations) are derived to other integral forms involving mean of BFDs.

The second approach of RNFs is bounds approach that can be found in such as Barlow [14], Barlow and Proschan [15], Marshall [16], Ayhan et al. [17], Leadbetter [18], Ozbaykal [12], Ran et al. [19], Politis and Koutras [20], and Xie [21]. The third approach of RNFs is based on simulations. One of the simulations is proposed by Blischke and Murthy [1]. The simulations based on Monte Carlo (MC) method are proposed by Brown et al. [22], and Kaminskiy and Krivtsov [23] who apply it on G-renewal process.

The last approach of RNFs is obtaining RNFs through numerical integration method. The method is applied in the integral equation forms of RNFs, called the renewal integral equations (RNIEs). The one numerical integration method is done through cubic spline method that is proposed by Cleroux and McConalogue [24], and then it is developed by Baxter et al. [25] for Weibull, Gamma, Lognormal, truncated Normal, and inverse Gaussian BFD. Deligönül and Bilgen [26] propose a method using cubic spline and Galerkin technique to obtain RNFs. The well-known numerical integration method is RiemannStieljies (RS) method that is proposed by Min Xie [8]. He states that "the method is surprisingly accurate (no need for small step length), fast (10-fold time saving), and simple (20-line BASIC programme)" [8]. Moreover, Elsayed [27] and Maghsoodloo-Helvaci [2] propose Mean Value Theorem for Integrals (MeVTI) method to obtain RNFs. However, the MeVTI method consumes more computational time eventhough the estimation of RNF at $t$ is accurate for sufficiently small subintervals [2].

This paper proposes a numerical integration method for estimating RNFs which is expressed as the solution of RNIEs through the same method that is proposed by Maghsoodloo and Helvaci [2], MeVTI method. However, we modify the variable of RNIEs then we apply MeVTI on it into a new numerical expression that is different from what they have. Maghsoodloo and Helvaci [2] compute RNFs backward recursively. We do it forward recursively, and we try to obtain an effective and efficient Matlab code programme to minimize computational time of MeVTI method. The effectiveness of the method is to be our purpose based on the accuracy of the estimation compared against the existing analytical approach of RNFs, those are for Exponential, Erlang, Gamma, and Normal baseline failure distributions. We also estimate RNF for a Weibull BFD using the method, then we compare the estimation of the RNF to that of the RS and cubic spline methods.

\section{Preliminaries}

Suppose $T_{n}$ denotes the time of the $n$-th component failure for $n=1,2,3, \ldots$, and $X_{n}$ denotes time between the $n$-th and the $(n-1)$-th component failure or $X_{n}=T_{n}-T_{n-1}$ where $T_{0}=0$. It is clear that $T_{n}$ and $X_{n}$ are nonnegative random variables (RVs) and $T_{n}=\sum_{i=1}^{n} X_{i}$. The $X_{n}$ is also known as interfailure time RV. Then, $N(t)$ is one-dimensional counting process or nonnegative RV denoting number of failures in time interval $[0, t)$. The $T_{n}, X_{n}$, and $N(t)$ have same events or sets of equivalent times those are

$$
\left\{t \mid N_{1}(t) \geq n\right\} \equiv\left\{t \mid T_{n} \leq t\right\} \equiv\left\{t \mid \sum_{i=1}^{n} X_{i} \leq t\right\}
$$

We assume all failed components are replaced by new and identical components, and time to replace is short so that can be negligible. Suppose $T_{1}$ (or $X_{1}$ ) has cumulative distribution function (cdf) $F(t)$, we consider $X_{i}$, for $i=1,2,3, \ldots, n$, independently and identically distributed (i.i.d.) to the $T_{1}$ that has $F(t)$. Then $T_{n}=\sum_{i=1}^{n} X_{i}$ has $F^{(n)}(t)$, called $n$-fold convolution of $F(t)$ with itself. Therefore, probability of $N(t)=n$ is obtained by

$$
\operatorname{Pr}[N(t)=n]=\operatorname{Pr}[N(t) \geq n]-\operatorname{Pr}[N(t) \geq n+1]=\operatorname{Pr}\left[T_{n} \leq t\right]-\operatorname{Pr}\left[T_{n} \leq t\right]=F^{(n)}(t)-F^{(n+1)}(t)
$$

So the expected number of failures in time interval $[0, t)$ is given by

$$
M(t)=E[N(t)]=\sum_{n=1}^{\infty} n \operatorname{Pr}[N(t)=n]=\sum_{n=1}^{\infty} F^{(n)}(t)
$$

There are two forms of RNIEs as the solutions of (1), those are 


$$
\begin{aligned}
& M(t)=F(t)+\int_{0}^{t} M(t-u) d F(u) \\
& M(t)=F(t)+\int_{0}^{t} F(t-u) d M(u)
\end{aligned}
$$

We see in both side of (2a) and (2b) have unknown function $M$. That is one of the reason why a RNF is difficult and complicated to obtain it analytically. Sometimes, a RNF can be obtained analytically through (1) for several BFD such as Exponential, Normal, and Gamma BFD [2]. Moreover, a RNF which is expressed as in (2a) and (2b) can be solved with Laplace transform such as RNF for a Erlang BFD with $k$-stages [1]. In Section 3, we will explain the existing analytical approach of RNFs.

Min Xie [8] estimates (2b) by using the RS method. Maghsoodlo and Helvaci [2] estimate (2a) by using the MeVTI method. We develope the MeVTI method where we will explain in Section 4.

\section{The Existing Analytical Approaches of Renewal Functions}

In this time, we explain analytical approach of RNFs those are the RNF for a Exponential, Erlang, Gamma, and Normal BFDs.

\subsection{The Renewal Function for a Exponential BFD}

The probability density function (pdf) of Exponential distribution with parameter $\lambda$ is given by $f(t)=\lambda e^{=\lambda t}$, and $n$-fold convolution of $f(t)$ itself is given by $f^{(n)}(t)=\lambda(\lambda t)^{n-1} e^{-\lambda t} / \Gamma(n)$. Since $F^{(n)}(t)=\int_{0}^{t} f^{(n)}(u) d u$, by using (1), the RNF is obtained by

$$
\begin{aligned}
M(t)=\sum_{n=1}^{\infty} F^{(n)}(t) & =\sum_{n=1}^{\infty} \int_{0}^{t} \lambda(\lambda u)^{n-1} e^{-\lambda u} / \Gamma(n) d u \\
& =\int_{0}^{t} \lambda e^{-\lambda u}\left[\sum_{n=1}^{\infty}\left((\lambda u)^{n-1} /(n-1) !\right)\right] d u=\int_{0}^{t} \lambda d u=\lambda t
\end{aligned}
$$

The RNF for a Exponential BFD with parameter $\lambda$ is given $b, M(t)=\lambda t$

This case where interfailure time RVs have an Exponential distribution with $\lambda$ constant rate is also known as Homogenuous Poisson Process.

\subsection{The Renewal Function for a Erlang BFD with $k$-Stages}

Erlang distribution with $k$-stages (parameter $\lambda$ ) has cumulative distribution function $F(t)=1-$ $e^{-\lambda t}\left\{\sum_{j=0}^{k-1}(\lambda t)^{j} / j !\right\}$. Through Laplace transform (the derivation can be found in Barlow and Proschan $[15])$, the RNF is given by

$$
M(t)=\frac{\lambda t}{k}+\frac{1}{k} \sum_{j=1}^{k-1} \frac{\theta^{j}\left\{1-e^{-\lambda t\left(1-\theta^{j}\right)}\right\}}{1-\theta^{j}}
$$

where $\theta=\exp (2 \pi i / k)$ with $i=\sqrt{-1}$. For $k=2$ stages, we have

$$
M(t)=\frac{2 \lambda t-1+e^{-2 \lambda t}}{4}
$$

\subsection{The Renewal Function for a Gamma BFD}

The $n$-fold convolution of $F(t)$ itself, where $F(t)$ is Gamma cdf with parameters $\alpha$ and $\lambda$, is given by $F^{(n)}(t)=\int_{0}^{t} \lambda(\lambda u)^{n \alpha-1} e^{-\lambda u} / \Gamma(n \alpha) d u$ [2]. By using (1), the RNF is obtained by $M(t)=$ $\sum_{n=1}^{\infty} \int_{0}^{t} \lambda(\lambda u)^{n \alpha-1} e^{-\lambda u} / \Gamma(n \alpha) d u$. By modifying variable $v=\lambda u[28]$,

$$
M(t)=\sum_{n=1}^{\infty} \int_{0}^{\lambda t} v^{n \alpha-1} e^{-v} / \Gamma(n \alpha) d v=\sum_{n=1}^{\infty} \Gamma(n \alpha ; \lambda t)
$$

where $\Gamma(n \alpha ; \lambda t)$ is incomplete Gamma function (can be seen in Matlab's function browser: gammainc). 


\subsection{The Renewal Function for a Normal BFD}

We know that a RV of the Normal distribution has support in $(-\infty, \infty)$. If interfailure time RVs, $X_{i}$ where $i=1,2,3, \ldots, n$, are NID (Normal and Independently Distributed) with mean $\mu$ and variance $\sigma^{2}$, then it cannot be applied in reliability analysis (since interfailure times must be nonnegative) at least if coefficient of variation is less than or equal to $15 \%, C V=\sigma / \pi \leq 15 \%$. That will make us to consider that the interfailure times can be applied since the probability interfailure times below zero is less than $10^{-10}$. If the $C V$ is not sufficiently small, then the truncated Normal distribution can qualify as a baseline failure distribution [2].

From what we learn in statistical theory, if $X_{i}, i=1,2,3, \ldots, n$, are $\operatorname{NID}\left(\mu, \sigma^{2}\right)$, then $T_{n}=\sum_{i=1}^{n} X_{i}$ has $N\left(n \mu, n \sigma^{2}\right)$ distribution which the cdf of $N\left(n \mu, n \sigma^{2}\right)$ can be derived to the standardized Normal Deviate $F^{(n)}(t)=\Phi((t-n \mu) /(\sigma \sqrt{n}))$. Thus, by using (1), the RNF for a Normal BFD is given by

$$
M(t)=\sum_{n=1}^{\infty} F^{(n)}(t)=\sum_{n=1}^{\infty} \Phi\left(\frac{t-n \mu}{\sigma \sqrt{n}}\right)
$$

\section{The Numerical Integration Methods for Estimating Renewal Functions}

Two methods those we discuss in this paper are Riemann-Stieljies (RS) method proposed by Min Xie [8] and Mean Value Theorem for Integrals (MeVTI) method proposed by Maghsoodloo and Helvaci [2]. The cubic spline method can be found in Cleroux and McConalogue [24], Baxter et all [25], and Deligönül and Bilgen [26]. In this section, we also explain our work in developing MeVTI method.

\subsection{The Riemann-Stieljies Method}

Min Xie [8] uses RS method for estimating the RNIEs in (2b). Min Xie [8] claims the method is accurate, fast, and simple. He also tells this method does not need equal length of subintervals.

Based on RS theorem, for $n$ sub-interval $t_{0}=0<t_{1}<t_{2}<\cdots<t_{n}=t$, renewal function at $t_{i}$, $M\left(t_{i}\right)$, can be estimated by

$$
M\left(t_{i}\right)=F\left(t_{i}\right)+\sum_{j=1}^{i} F\left(t_{i}-t_{i-\frac{1}{2}}\right)\left[M\left(t_{i}\right)-M\left(t_{i-1}\right)\right]
$$

Min Xie [8] gets a set of linear equations from (7). Then he solve and translate it into 20-line BASIC programme.

\subsection{The Mean Value Theorem for Integrals (MeVTI) Method by Maghsoodloo-Helvaci}

Maghsoodloo and Helvaci [2] propose MeVTI method for estimating the RNIEs in (2a). They note this method is accurate for sufficiently small subintervals. However, this method consumes more computational time. They also tell that it needs to discretize a time interval into $n$ subinterval those have equal length.

Based on MeVTI, for $n$ sub-interval $t_{0}=0<t_{1}<t_{2}<\cdots<t_{n}=t$, renewal function at $t_{i}=i \Delta t$ where $\Delta t=t / n, M\left(t_{i}\right)$, can be estimated by

$$
M\left(t_{i}\right)=\sum_{j=1}^{i}\left(1+M\left(t_{i}-t_{j}\right)\right)\left(F\left(t_{j}\right)-F\left(t_{j-1}\right)\right)
$$

They estimate $M\left(t_{i}\right)$ backward recursively which starts from $j=i$, then at $j=i-1, j=i-2, \ldots, j=1$. After all, they sum $\left(1+M\left(t_{i}-t_{j}\right)\right)\left(F\left(t_{j}\right)-F\left(t_{j-1}\right)\right)$ for $j=1,2, \ldots i$. What they do seems complicated and has a long time computational.

\subsection{The Modified MeVTI method}

We develop MeVTI method which has different way from what Maghsoodloo and Helvaci [2] do. First, we derive (2a) into

$$
M(t)=F(t)+\int_{0}^{t} M(t-u) d F(u)=\int_{0}^{t} d F(u)+\int_{0}^{t} M(t-u) d F(u)
$$




$$
=\int_{0}^{t}[1+M(t-u)] d F(u)
$$

We modify variable in (9) that is $u=t-v \Rightarrow d u=-d v$. Thus, $F(u)=F(t-v) \Rightarrow D_{v}[F(t-v)]=$ $-f(t-v)$. It is clear that $d F(u)=f(u) d u=-f(t-v) d v=d F(t-v)$. When $u=0 \Longrightarrow v=t$ and $u \rightarrow t \Longrightarrow v \rightarrow 0$. Then,

$$
M(t)=\int_{t}^{0}[1+M(v)] d F(t-v)=-\int_{0}^{t}[1+M(v)] d F(t-v)
$$

With dividing $[0, t)$ into $n$ subinterval those have equal length, $t_{0}<t_{1}<t_{2}<\cdots<t_{n}$ where $t_{i}=i \Delta t$ and $\Delta t=t / n$, equation (10) becomes

$$
\begin{gathered}
M(t)=-\left[\int_{t_{0}}^{t_{1}}[1+M(v)] d F(t-v)+\int_{t_{1}}^{t_{2}}[1+M(v)] d F(t-v)+\cdots\right. \\
\left.\quad+\int_{t_{n-2}}^{t_{n-1}}[1+M(v)] d F(t-v)+\int_{t_{n-1}}^{t}[1+M(v)] d F(t-v)\right] \\
=\sum_{i=1}^{n}\left[-\int_{t_{i-1}}^{t_{i}}[1+M(v)] d F(t-v)\right]
\end{gathered}
$$

We apply MeVTI at the left point of all subintervals, thus

$$
\begin{aligned}
M(t)=\sum_{i=1}^{n}[ & {\left.\left[1+M\left(t_{i-1}\right)\right]\left(-\int_{t_{i-1}}^{t_{i}} d F(t-v)\right)\right] } \\
& =\sum_{i=1}^{n}\left[1+M\left(t_{i-1}\right)\right]\left[F\left(t-t_{i-1}\right)-F\left(t-t_{i}\right)\right]
\end{aligned}
$$

The estimation of $M\left(t_{i}\right)$ in (12) can be obtained forward recursively through

$$
M\left(t_{i}\right)=\sum_{j=1}^{i}\left[1+M\left(t_{j-1}\right)\right]\left[F\left(t-t_{j-1}\right)-F\left(t-t_{j}\right)\right]
$$

for $i=1,2,3, \ldots, n$, where $M(0)=F(0)=0$ and $M\left(t_{1}\right)=F\left(t_{1}\right)$.

We give algorithm of our modified MeVTI method. One of Matlab code programmes is also given. The algorithm and code are made by translating (13) into operation of vectors. Matlab programme has an important role in helping our computational based on operation of vectors. We use Matlab R2012a. Our device is a laptop which has quad core processor with maximum clock speed @ $1.7 \mathrm{Ghz}$ and 2 Gb RAM.

\subsection{Algorithm of the Modified MeVTI Method}

1. Initialization

- provide $t, n, \Delta t=t / n$, and $k=3$,

- vector $\boldsymbol{T}_{(n+1) \times 1}=\left[T_{i}\right]_{i=1}^{n+1}$, where $T_{i}=(i-1) \Delta t$,

- vector $\boldsymbol{M}_{1 \times(n+1)}=[0]_{i=1}^{n+1}$, then fill $M_{2}=F\left(T_{2}\right)$.

2. Process
a. If $k>n+1$, go to 3. If else, go to 2.b,
b. calculate vector $\boldsymbol{u}=T_{k}-\left[T_{i}\right]_{i=1}^{k-1}$ and $v=T_{k}-\left[T_{i}\right]_{i=2}^{k}$,
c. calculate vector $\boldsymbol{G}=F(\boldsymbol{u})-F(\boldsymbol{v})$,
d. calculate $k$-th entry of vector $\boldsymbol{M}, M_{k}=\left(1+[M]_{i=1}^{k-1}\right) \cdot \boldsymbol{G}$,
e. calculate $k=k+1$, go to 2.a.

3. Output : the estimation of RNF at $t, M_{n+1}$. 
This following code programme estimates renewal function for a Exponential BFD with parameter $\lambda=0.001(\mu=1 / \lambda=1000)$ at $t=10000$ for $n=100$.

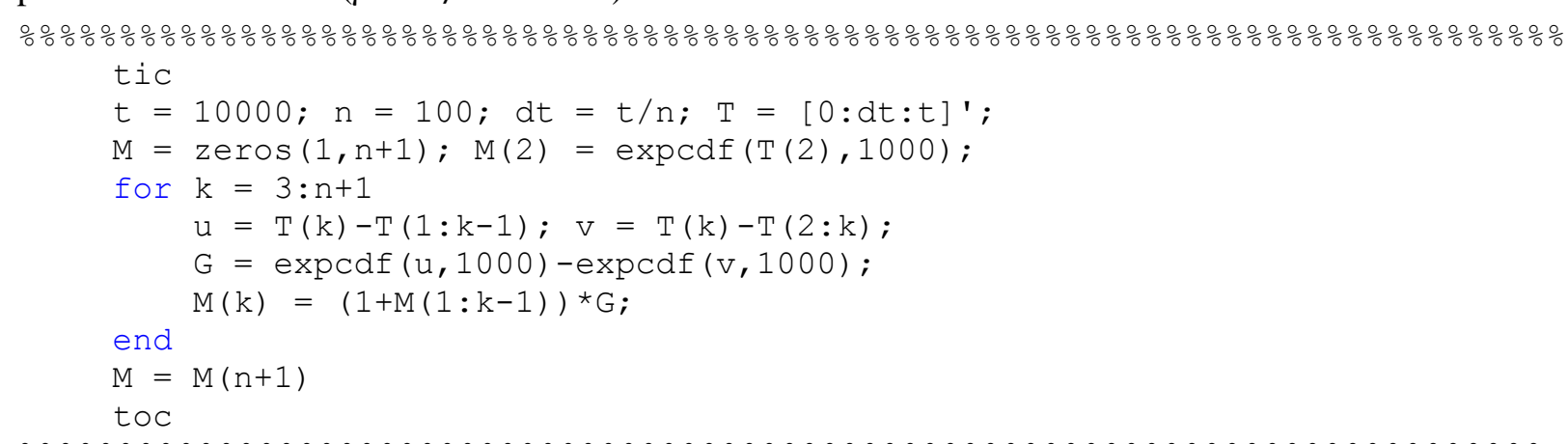

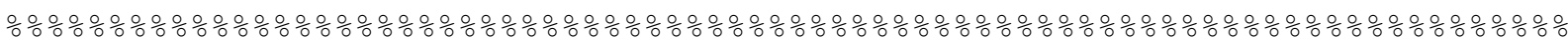

\section{Results and Discussions}

This section has five parts of discussion. The first four parts discuss about the estimation of four RNFs (the RNF for a Exponential, Erlang, Gamma, and Normal BFDs) using our modified MeVTI method. We compare the estimation to their analytical approaches. The last part discuss the estimation of the RNF for a Weibull BFD using our modified MeVTI method and its comparison against the estimation of the RNF using RS and cubic spline methods.

\subsection{The Estimation of the RNF for a Exponential BFD}

We estimate the RNF for Exponential BFD with $\lambda=0.001$ at $t=10000$ as Maghsoodloo and Helvaci [2] do. Based on (3), the exact value of the RNF is $M(10000)=(0.001)(10000)=10$. Tabel 1 gives the results.

Tabel 1. Comparison of MeVTI Methods with Exact Value of $M(t)$ for the Exponential BFD

\begin{tabular}{|c|c|c|c|c|c|c|}
\hline \multirow{2}{*}{$\Delta t$} & \multirow{2}{*}{$\begin{array}{c}\text { Exact } \\
\text { Value of } \\
M(t)\end{array}$} & \multicolumn{2}{|c|}{$\begin{array}{l}\text { Maghsoodlo-Helvaci's MeVTI } \\
\text { Method }\end{array}$} & \multicolumn{3}{|c|}{ Our Modified MeVTI Method } \\
\hline & & $M(t)$ & $\begin{array}{l}\text { Elapsed time } \\
(\mathrm{sec})\end{array}$ & $M(t)$ & $\begin{array}{l}\text { Relative } \\
\text { error }\end{array}$ & $\begin{array}{l}\text { Elapsed time } \\
(\mathrm{sec})\end{array}$ \\
\hline 250 & 10 & 8.8479686771438 & 21.066944 & 8.847968677143806 & $-11.5203 \%$ & 0.001378 \\
\hline 200 & 10 & 9.0634623461009 & 32.320588 & 9.063462346100907 & $-9.3654 \%$ & 0.002120 \\
\hline 100 & 10 & 9.5162581964040 & 65.112829 & 9.516258196404042 & $-4.8374 \%$ & 0.004000 \\
\hline 50 & 10 & 9.7541150998572 & 82.738732 & 9.754115099857199 & $-2.4589 \%$ & 0.009976 \\
\hline 25 & 10 & 9.8760351886669 & 2018.707614 & 9.876035188666933 & $-1.2397 \%$ & 0.021733 \\
\hline 10 & 10 & 9.9501662508319 & 40238.617140 & 9.950166250831945 & $-0.4983 \%$ & 0.078848 \\
\hline
\end{tabular}

Based on Table 1, our modified MeVTI method gives the same results with the results of Maghsoodlo-Helvaci's MeVTI method [2] until 13 numbers behind comma. Thus, we give the relative error of the both method to the exact value of $M(t)$ at 6th column. The computational time through our algorithm and code programme is incredibly fast. It seems that the algorithm and code programme are more efficient. According to these results, we can say that (8) is equal to (13).

For smaller subinterval, we have the estimation of $M(t)$ using our modified MeVTI method in Table 2.

Tabel 2. The RNF for the Exponential BFD using Our Modified MeVTI Method for Smaller Subinterval

\begin{tabular}{|c|c|c|c|c|}
\hline \multirow{2}{*}{$\Delta \boldsymbol{t}$} & Exact Value of & \multicolumn{3}{|c|}{ Our Modified MeVTI Method } \\
\cline { 3 - 5 } & $\boldsymbol{M}(\boldsymbol{t})$ & $M(t)$ & Relative error & Elapsed time $(\mathrm{sec})$ \\
\hline $\mathbf{1}$ & 10 & 9.995001666250083 & $-0.0500 \%$ & 5.469037 \\
\hline $\mathbf{0 . 5}$ & 10 & 9.997500416614589 & $-0.0250 \%$ & 19.068695 \\
\hline $\mathbf{0 . 2}$ & 10 & 9.999000066663333 & $-0.0100 \%$ & 108.412236 \\
\hline $\mathbf{0 . 1}$ & 10 & 9.999500016666252 & $-0.0050 \%$ & 429.085511 \\
\hline
\end{tabular}

For $[0,10000)$ divided into 100000 subintervals $(\Delta t=0.1)$, the elapsed time is 8 minutes. However, for $\Delta t=0.2$ or 50000 subintervals, the elapsed time is less than 2 minutes. It shows that our algorithm and 
code programme are still efficient in sufficiently small subintervals or until 50000 subintervals. Since the relative error goes to $0 \%$ as $\Delta t$ goes to 0 , our algorithm and code programme are also effective.

\subsection{The Estimation of the RNF for a Erlang BFD with 2-Stages}

In this part, we estimate the RNF for Erlang BFD with 2 stages as seen in $(4 b)$ where $\lambda=1$ at $t=$ 5. Analytically, The RNF is $M(5)=\left(10-1+e^{-10}\right) / 4=2.250011$.

Tabel 3. The Estimation of the RNF for the Erlang BFD with 2 Stages

\begin{tabular}{|c|c|c|c|c|}
\hline \multirow{2}{*}{$\Delta \boldsymbol{t}$} & \multirow{2}{*}{$\begin{array}{c}\text { Exact Value } \\
\boldsymbol{o f}\end{array}$} & \multicolumn{3}{|c|}{ Our Modified MeVTI Method } \\
\cline { 3 - 5 } & $\boldsymbol{M}(\boldsymbol{t})$ & $M(t)$ & Relative error & Elapsed time (sec) \\
\hline $\mathbf{1}$ & 2.250011 & 1.862547 & $-17.2205 \%$ & 0.002039 \\
\hline $\mathbf{0 . 5}$ & 2.250011 & 2.032597 & $-9.6628 \%$ & 0.004033 \\
\hline $\mathbf{0 . 0 5}$ & 2.250011 & 2.225382 & $-1.0946 \%$ & 0.067058 \\
\hline $\mathbf{0 . 0 0 5}$ & 2.250011 & 2.247514 & $-0.1109 \%$ & 0.090879 \\
\hline $\mathbf{0 . 0 0 1}$ & 2.250011 & 2.249511 & $-0.0222 \%$ & 1.605724 \\
\hline $\mathbf{0 . 0 0 0 5}$ & 2.250011 & 2.249761 & $-0.0111 \%$ & 6.192392 \\
\hline $\mathbf{0 . 0 0 0 1}$ & 2.250011 & 2.249961 & $-0.0022 \%$ & 141.107192 \\
\hline
\end{tabular}

Based on Table 3, the relative error goes to $0 \%$ as $\Delta t$ goes to 0 . For $50000(\Delta t=0.0001)$, the computational time is less than 3 minutes.

\subsection{The Estimation of the RNF for a Normal BFD}

Here we estimate the RNF for Normal BFD with $\mu=15$ and $\sigma^{2}=2.25$ at $t=42$. Thus, $C V=$ $\sigma / \pi=(1.5) /(15)=10 \%$. Based on (6) and [2], $M(42)=2.124107$.

Tabel 4. The Estimation of the RNF for the Normal BFD

\begin{tabular}{|c|c|c|c|c|}
\hline \multirow{2}{*}{$\Delta \boldsymbol{t}$} & \multirow{2}{*}{$\begin{array}{c}\text { Exact Value of } \\
\boldsymbol{M}(\boldsymbol{t})\end{array}$} & \multicolumn{3}{|c|}{ Our Modified MeVTI Method } \\
\cline { 3 - 5 } & 2.124107 & $M(t)$ & Relative error & Elapsed time $(\mathrm{sec})$ \\
\hline $\mathbf{1}$ & 2.064140 & $-2.8231 \%$ & 0.004438 \\
\hline $\mathbf{0 . 1}$ & 2.124107 & 2.116426 & $-0.3616 \%$ & 0.076581 \\
\hline $\mathbf{0 . 0 1}$ & 2.124107 & 2.123320 & $-0.0371 \%$ & 2.632645 \\
\hline $\mathbf{0 . 0 0 1}$ & 2.124107 & 2.124028 & $-0.0037 \%$ & 177.208774 \\
\hline
\end{tabular}

Based on Table 3, the relative error goes to $0 \%$ as $\Delta t$ goes to 0 . For $42000(\Delta t=0.001)$, the computational time is less than 3 minutes.

\subsection{The Estimation of the RNF for a Gamma BFD}

The estimation of the RNF for Gamma BFD with $\alpha=2$ and $\lambda=1$ at varies value of $t$ through approximation approach by Bartholomew [11] $M_{b}(t)$, Ozbaykal [12] $M_{o}(t)$, Deligönül [13] $M_{d e}(t)$, and analytical approach that is given by Blischke and Murthy [1], $M(t)=\left(t-1+e^{-t}\right) / 4$, and the estimation of the RNF through our modified MeVTI method $(\Delta t=0.001)$ are given in Table 5.

Tabel 5. The Estimation of the RNF for the Gamma BFD through Several Approaches

\begin{tabular}{|c|c|c|c|c|c|c|c|}
\hline \multirow[b]{2}{*}{$\boldsymbol{t}$} & \multirow{2}{*}{$\begin{array}{c}\text { Bartholomew } \\
M_{b}(t)\end{array}$} & \multirow{2}{*}{$\begin{array}{c}\text { Ozbaykal } \\
M_{o}(t)\end{array}$} & \multirow{2}{*}{$\begin{array}{c}\text { Deligönü̈l } \\
M_{d e}(t)\end{array}$} & \multirow{2}{*}{$\begin{array}{c}\text { Exact Value } \\
\text { of } M(t)\end{array}$} & \multicolumn{3}{|c|}{ Our Modified MeVTI Method } \\
\hline & & & & & $M(t)$ & $\begin{array}{l}\text { Relative } \\
\text { error }\end{array}$ & $\begin{array}{c}\text { Elapsed time } \\
\text { (sec) }\end{array}$ \\
\hline 0.2 & 0.01760 & 0.09562 & 0.01760 & 0.01758 & 0.01758 & $-0.0000 \%$ & 0.032704 \\
\hline 0.4 & 0.06262 & 0.18461 & 0.06261 & 0.06233 & 0.06233 & $-0.0000 \%$ & 0.079816 \\
\hline 0.6 & 0.12640 & 0.26952 & 0.12631 & 0.12530 & 0.12529 & $-0.0080 \%$ & 0.162975 \\
\hline 0.8 & 0.20313 & 0.35520 & 0.20285 & 0.20047 & 0.20045 & $-0.0100 \%$ & 0.287436 \\
\hline 1.0 & 0.28880 & 0.43394 & 0.28814 & 0.28383 & 0.28380 & $-0.0106 \%$ & 0.447523 \\
\hline 1.2 & 0.38067 & 0.51566 & 0.37937 & 0.37268 & 0.37263 & $-0.0134 \%$ & 0.657841 \\
\hline 1.4 & 0.47678 & 0.59796 & 0.47454 & 0.46520 & 0.46513 & $-0.0150 \%$ & 0.885471 \\
\hline 1.6 & 0.57575 & 0.68123 & 0.57225 & 0.56019 & 0.56010 & $-0.0161 \%$ & 1.176094 \\
\hline
\end{tabular}




\begin{tabular}{|c|c|c|c|c|c|c|c|}
\hline \multirow[b]{2}{*}{$t$} & \multirow{2}{*}{$\begin{array}{c}\text { Bartholomew } \\
M_{b}(t)\end{array}$} & \multirow{2}{*}{$\begin{array}{c}\text { Ozbaykal } \\
M_{o}(t)\end{array}$} & \multirow{2}{*}{$\begin{array}{c}\text { Deligönü̈l } \\
M_{d e}(t)\end{array}$} & \multirow[b]{2}{*}{$\begin{array}{l}\text { Exact Value } \\
\text { of } M(t)\end{array}$} & \multicolumn{3}{|c|}{ Our Modified MeVTI Method } \\
\hline & & & & & $M(t)$ & $\begin{array}{c}\text { Relative } \\
\text { error }\end{array}$ & $\begin{array}{l}\text { Elapsed time } \\
(\mathrm{sec})\end{array}$ \\
\hline 1.8 & 0.67663 & 0.76571 & 0.67151 & 0.65683 & 0.65672 & $-0.0167 \%$ & 1.530336 \\
\hline 2.0 & 0.77871 & 0.85150 & 0.77166 & 0.75458 & 0.75445 & $-0.0172 \%$ & 1.912525 \\
\hline 3.0 & 1.29458 & 1.29979 & 1.27411 & 1.25062 & 1.25037 & $-0.0200 \%$ & 4.410673 \\
\hline 4.0 & 1.80740 & 1.77289 & 1.77143 & 1.75008 & 1.74971 & $-0.0211 \%$ & 7.406144 \\
\hline 5.0 & 2.31475 & 2.26011 & 2.26546 & 2.25001 & 2.24951 & $-0.0222 \%$ & 11.124587 \\
\hline 8.0 & 3.82099 & 3.75075 & 3.74982 & 3.75000 & 3.74913 & $-0.0231 \%$ & 24.634114 \\
\hline
\end{tabular}

For varies value of $t$, the relative errors have mean $-0.0150 \%$ with the computational time less than 1 minute.

\subsection{The Estimation of the RNF for a Weibull BFD}

We also estimate the RNF for unknown convolution that is the RNF for the Weibull BFD with $\lambda=1$ and $\beta=0.5$ at varies value of $t$. The results is also compared to the results through cubic spline method by Baxter et al. (can be seen in [25]) and RS method by Min Xie. The interval $[0, t$ ) is divided into $n$ subintervals with $\Delta t=0.001$. The comparison can be seen in Table 6 .

Tabel 6. The Estimation of the RNF for the Weibull BFD through Several Numerical Approaches

\begin{tabular}{|c|c|c|c|c|c|}
\hline \multirow[t]{2}{*}{$t$} & \multirow{2}{*}{$\begin{array}{c}\begin{array}{c}\text { Cubic Spline } \\
\text { Method }\end{array} \\
M(t)\end{array}$} & \multicolumn{2}{|c|}{ Riemann Stieljies Method } & \multicolumn{2}{|c|}{$\begin{array}{c}\text { Our Modified MeVTI } \\
\text { Method }\end{array}$} \\
\hline & & $M(t)$ & Elapsed time (sec) & $M(t)$ & Elapsed time (sec) \\
\hline 1 & 1.3077 & 1.3080 & 0.023169 & 1.3072 & 0.336874 \\
\hline 2 & 2.0478 & 2.0476 & 0.074976 & 2.0466 & 0.496255 \\
\hline 3 & 2.7018 & 2.7014 & 0.167590 & 2.7003 & 0.750203 \\
\hline 4 & 3.3141 & 3.3134 & 0.297046 & 3.3120 & 1.382846 \\
\hline 5 & 3.9010 & 3.9001 & 0.462873 & 3.8987 & 2.063057 \\
\hline
\end{tabular}

Based on Table 5, for each numerical approaches, the results are not quite different. However, we can not determine which method is the best since we do not have the exact value of the RNF for the Weibull BFD. We are only capable to compare the computational time between our modified MeVTI method and RS method. The RS method by Min Xie is more efficient than our modified MeVTI method although we ever make our algorithm and code programme with single global looping because of operation of vectors.

\section{Conclusions}

We provided our modified MeVTI method to estimate the RNFs in the terms of renewal integral equations (RNIEs) based on developing the MeVTI method proposed by Maghsoodloo and Helvaci. The development is done on (2a) by modifying its variable. We got that (8) is equal to (13).

We also provided algorithm and code programme for our modified MeVTI method. The algorithm and code programme are effective and efficient based on our laptop specification that we have. We applied our modified MeVTI method to estimate the RNFs for Exponential, Erlang, Normal, and Gamma BFD. We got that our modified MeVTI method gives accurate results for sufficiently small subintervals and has efficient computational time that calculates values at 50000 subintervals less than 3 minutes.

We also applied our modified MeVTI method to estimate the RNF for unknown convolution that is for Weibull BFD. The estimation of the RNF is not quite different to the estimation of the RNF using RS and cubic spline methods. However, the computational time of the RS method proposed by Min Xie is more efficient than the computational time of our modified MeVTI method.

\section{Acknowledgements}

The authors thank Asian Mathematical Conference 2016 for the chance to present this paper in oral presentation. 


\section{References}

[1] W.R. Blischke and D.N.P. Murthy, Warranty cost analysis (London, Marcel Dekker, 1994).

[2] S. Maghsoodloo and D. Helvaci, Renewal and renewal-intensity function with minimal repair, Journal of Quality and Reliablity Engineering, 2014, ID : 857437.

[3] W.R. Blischke, M.R. Karim, and D.N.P. Murthy, Warranty data collection and analysis, (London, Springer Series in Reliability Engineering, 2011).

[4] J. Baik, D.N.P. Murthy, and N. Jack, Two-dimensional failure modeling with minimal repair, Naval Research Logistics, 51, 2004, 345-362.

[5] S. Täcklind, Fourieranalytische behandlung vom erneuerungs problem, Scandinavian Actuarial Journal, 1945(1-2), 68-105.

[6] S.M. Ross, Applied probability models with optimization applications (San Francisco, Holden-Day, 1970).

[7] E. Cinlar, Introduction to Stochastic Processes (Englewood Cliffs, NJ: Prentice-Hall, 1975).

[8] M. Xie, On the solution of renewal-type integral equations, Communication Statistics Simulation Computation, 18(1), 1989, 281-293.

[9] W.L. Smith and M.R. Leadbetter, On the renewal function for the weibull distribution, Technometrics, 5(3), 1963, 393-396.

[10] Z.A. Lomnicki, A note on the weibull renewal process, Biometrika, 53(3-4), 1966, 375-381.

[11] D.J. Bartholomew, An approximate solution of the integral equation of renewal theory, Journal of Royal Statistics Society, 25(B), 1963, 432-441.

[12] T. Ozbaykal, Bounds and approximations for the renewal function, M.S. Thesis, Department of Operations Research, Naval Postgraduate School, Monterrey, CA, 1971.

[13] Z.S. Deligönül, An approximate solution of the integral equation of the renewal theory, Journal of Applied Probability, 22, 1985, 926-931.

[14] R.E. Barlow, Bounds on integrals with applications to reliability, The Annals of Mathematical Statistics, 36(2), 1965, 565-574.

[15] R.E. Barlow and F. Proschan, Statistical theory of reliability and life testing, To Begin With, Silver Spring, MD, 1981.

[16] K.T. Marshall, Linear bounds on the renewal function, SIAM Journal on Applied Mathematics, 24(2), 1973, 245-250.

[17] H. Ayhan, J. Limon-Robles, and M.A.Wortman, An approach for computing tight numerical bounds on renewal functions, IEEE Transactions on Reliability, 48(2), 1999, 182-188.

[18] M.R. Leadbetter, Bounds on the error in the linear approximation to the renewal function, Biometrika, 51(3-4), 1964, 355-364.

[19] L. Ran, L.R. Cui, and M. Xie, Some analytical and numerical bounds on the renewal function, Communications in Statistics-Theory And Methods, 35(10), 2006, 1815-1827.

[20] K. Politis and M.V. Koutras, Some new bounds for the renewal function, Probability in the Engineering and Informational Sciences, 20, 2006, 231-250.

[21] M. Xie, Some results on renewal equations, Communication in Statistics, 18(3), 1989, 1159-1171.

[22] M. Brown, H. Solomon, and M.A. Stephens, Monte Carlo simulation of the renewal function, Journal of Applied Probability, 18(2), 1981, 426-434.

[23] M. Kaminskiy and V. Krivtsov, A Monte Carlo approach to estimation of g-renewal process in warranty data analysis, Reliability: Theory and Applications, 2006(1), 29-31.

[24] R. Cleroux and D.J. McConalogue, A numerical algorithm for recursively defined convolution integrals involving distribution functions, Management Sciences, 22, 1976, 1138-1148. 
[25] L.A. Baxter, E.M. Scheuer, D.J. McConalogue, and W.R. Blischke, On the tabulation of the renewal function, Technometrics, 24, 1982, 151-156.

[26] Z.S. Deligönül and S. Bilgen, Solution of the Volterra equation of renewal theory with Galerkin technique using cubic splines, Journal of Statistics Computation and Simulation, 20, 1984, 37-45.

[27] E.A. Elsayed, Reliability Engineering (Hoboken, NJ: John Wiley \& Sons, 2012).

[28] C.E. Ebeling, An Introduction to Reliability and Maintainability Engineering (LongGrove, WavelandPress, 2010). 